\title{
LUA NO VARAL, DE ANTONIO BARRETO E A FUNÇÃO HUMANIZADORA DA ARTE
}

\author{
Luciana FERREIRA LEAL (FACULDADES FACCAT luciana_lea@hotmail.com)
}

O objetivo do trabalho consiste em analisar as funções da Literatura, de acordo com Antonio Candido em A Literatura e a formação do Homem, no livro Lua no varal, de Antonio Barreto. O texto de Lua no varal, de Antonio Barreto, é um livro de poesia composto de tempo, infância, cores, sabores, cheiros, texturas, brincadeira e, sobretudo, imaginação. Com outro significado, a paisagem do cotidiano é enriquecida com imagens e poesia. Em vez de estender a roupa, o leitor é convidado para estender, no varal, o sonho. As memórias, os sentimentos, o conhecimento e a vida são pendurados no fio de tempo que possui valor incomensurável. Com muito lirismo e absoluta poeticidade, a poesia deste livro conduz o leitor ao instigante universo do faz de conta, necessário a todas as idades. Antonio Candido identifica três funções exercidas pela Literatura, são elas: função psicológica, função formadora e função social, as quais, em seu conjunto, denomina de função humanizadora da Literatura. As três funções, identificadas por Antonio Candido, podem ser analisadas no livro em questão em que texto e ilustração se juntam para tratar da poesia, o que nos permite dupla leitura poética e humanizadora: a do texto e a da imagem.

Palavras chave: função humanizadora, Lua no varal, poesia.

\section{INTRODUÇÃO}

Antonio Candido identifica três funções exercidas pela Literatura, são elas: função psicológica (necessidade de fantasia), função formadora (as fantasias têm base na realidade) e função social (identificação do leitor e de seu universo vivencial), as quais, em seu conjunto, denomina de função humanizadora da Literatura. As três funções, identificadas por Antonio Candido, podem ser analisadas no livro em questão em que texto e ilustração se juntam para tratar da poesia, o que nos permite a dupla leitura poética e humanizadora: a do texto e a da imagem.

O livro possibilita ampliação das referências estéticas e culturais do leitor, visto que é um texto permeado de movimento, de sentido contrário, de abertura para o outro, é o texto que rompe o equilíbrio e faz pensar. A poesia contida em Lua no varal mostra aos leitores que existem várias maneiras de usar as palavras e a linguagem.

\section{LUA NO VARAL}

Lua no Varal, publicado em 1986, foi, em 2012, sob a responsabilidade do designer gráfico de Maurizio Mannzo, publicado sob nova edição. As ilustrações e projeto gráfico de Paulo Bernardo Vaz foram recuperadas, por meio de restauro digital. Foi mantido, no projeto gráfico, a concepção da estrutura original, apenas com mais área branca, nova tipografia e pequenos ajustes na nova diagramação do livro. 


\section{SEMINÁRIO DE PESQUISA EM CIÊNCIAS HUMANAS - SEPECH \\ Humanidades, Estado e desafios didático-científicos \\ Londrina, 27 a 29 de julho de 2016}

Lua no Varal é um livro destinado ao público infantil que encanta leitores de todas as idades. Chegou às minhas mãos como sonho, como sentimento a ser pendurado no fio do tempo e me seduziu imediatamente. Tinha a impressão de que as páginas, quando as virava, saiam ao vento para respirar e me acenava como convite para continuar a leitura. Tantas perguntas fiz para mim mesma: é possível pendurar a lua no varal? Como posso pendurar a lua no varal? Em vez da lua, penduro o sonho?

Com cores vivas, o ilustrador interpreta e ilumina os múltiplos sentidos da expressão "lua no varal" encontrados nesse livro. A Literatura forma, não pedagogicamente, mas humanamente. A função formadora é aqui entrevista na descoberta de um mundo de infinitas possibilidades, na descoberta das palavras, dos sons e das rimas. Os recursos expressivos da produção poética são muito bem utilizados em Lua no varal. Dividido em quatro grandes poemas: "A poça-d'água", "A lâmpada", "A serenata" e "A aurora", sugerindo momentos decisivos da noite e madrugada (do entardecer ao amanhecer), o livro é permeado de imagens poéticas, na maioria das vezes insólitas, efeitos rítmicos e elaboração lexical.

O autor, Antonio de Pádua Barreto Carvalho, nasceu em Passos (MG) em 13 de junho de 1954. Reside em Belo Horizonte desde 1973. Morou também em algumas cidades do Oriente Médio. Tem vários prêmios nacionais e internacionais de literatura, para obras inéditas e publicadas, nos gêneros: poesia, conto, romance e literatura infanto-juvenil. Participa também de várias antologias nacionais e estrangeiras de poesia e contos. Foi redator do Suplemento Literário do Minas Gerais, articulista e cronista do jornal Estado de Minas e da revista "Morada" (BH). Colabora com textos críticos, poemas e artigos de opinião para "El Clarín" (Buenos Aires), "Ror" (Barcelona); "Zidcht" (Frankfurt), "Somam" (Bruxelas); e outros periódicos.

O ilustrador, Paulo Bernardo Vaz, possui graduação em Comunicação Social, mestrado em Editoração e Audiovisual, diploma de estudos aprofundados (DEA) em Audiovisual e Telemática (1981), doutorado em Comunicação e Educação e PósDoutorado pela Universidade do Minho (2010). Professor Visitante junto ao Programa de Pós-Graduação em Jornalismo (Mestrado e Doutorado) da Universidade Federal de Santa Catarina e aposentado da Universidade Federal de Minas Gerais. Desenvolve pesquisas sobre design gráfico, fotojornalismo, imagem, tipografia e publicidade na mídia impressa.

\section{AS FUNÇÕES DA LITERATURA}

Professor, crítico e ensaísta Antonio Candido, mestre de todos nós, discorre acerca das funções que a literatura pode desempenhar na formação do homem. Segundo ele, as funções são: psicológica, formadora/educadora e social.

Na função psicológica, a literatura responde às necessidades humanas de ficção e fantasia. Essas necessidades são expressas por meio dos devaneios em que todos se envolvem diariamente. Em se tratando das modalidades de fantasia, para Candido, a literatura seja, talvez, a mais rica, pois é capaz de suprir, e transformar a realidade com o trabalho executado pela imaginação literária.

$\mathrm{Na}$ função formadora, a literatura formaria e educaria como a própria vida. Por ter base na realidade, a literatura atua como instrumento de educação, de formação do homem, não segundo a pedagogia oficial, ou como um apêndice de instrução moral e 


\section{SEMINÁRIO DE PESQUISA EM CIÊNCIAS HUMANAS - SEPECH \\ Humanidades, Estado e desafios didático-científicos \\ Londrina, 27 a 29 de julho de 2016}

cívica ou, ainda, como nos manuais de virtudes e boa conduta, mas trazendo em si tanto o bem quanto o mal e agindo de forma imprevisível na formação do homem, ela humaniza em sentido profundo, porque faz viver.

A terceira e última função considerada por Candido diz respeito ao conhecimento do mundo e do ser, à identificação do leitor e de seu universo vivencial e ele denomina de função social. Essa função é que faculta ao homem o reconhecimento da realidade que o cerca quando transposta para o mundo ficcional. Assim, essa função é verdadeiramente sentida quando o leitor é capaz de incorporar a realidade da obra às suas próprias vivências e experiências pessoais, ou seja, quando o leitor se sente participante de uma humanidade também sua, conseguindo incorporar à sua experiência o que o escritor lhe apresente como sentido de realidade.

Essas funções influem diretamente no homem, visto que a literatura, relacionada à demonstração do real, expressa o homem e, ao mesmo tempo, volta-se para sua formação, ao passo em que é fruidor da mesma. É notória a importância que a literatura exerce no meio social, principalmente no homem, participante e responsável pelo sustento e manutenção do seu meio.

Lua no varal (2012) trata-se de literatura de fato, pois neste livro encontramos as funções estabelecidas por Candido. A função psicológica permeia todo o texto. Nós leitores nos contagiamos com a imaginação literária oferecida pelo livro. As fantasias e devaneios também fazem parte do universo ficcional. Os recursos expressivos da produção poética são muito bem utilizados em Lua no varal (2012). Dividido em quatro grandes poemas: "A poça-d'água", "A lâmpada", "A serenata" e "A aurora", sugerindo momentos decisivos da noite e madrugada (do entardecer ao amanhecer), o livro é permeado de imagens poéticas: "Ali, na janela da noite,/ onde a Lua é uma queijo de mel,/ um menino lambe seus sonhos/ brincando com a lâmpada do céu" (p.7), na maioria das vezes insólitas: "mas aí um peixe de penas" (p.17), efeitos rítmicos: "E logo depois desse aviso/ no meio da praça da Farra/ surgiu a banda encantada/ do Circo Nacional de Milonga." (p.14) e elaboração lexical: "E o menino espichava a janela/pra ver se era tudo verdade:/ era a Lua encurralada na rua enluarada/dormindo bem fresquinha/ numa poça-d'água." (p.26).

E tudo acontece enquanto o menino lê uma história. Toda a imaginação e fantasia são decorrentes do livro que lê. Nesta metalinguagem, o autor aborda uma das principais características do texto literário - o despertar da imaginação e da fantasia: "do livro com seus labirintos/ saltam duendes, palavras, e assim, página por página,/ devora o que está escrito." (p.9)

A Literatura forma, não pedagogicamente, mas humanamente. A função formadora é aqui entrevista na descoberta de um mundo de infinitas possibilidades, na descoberta das palavras, dos sons e das rimas. Indiretamente, por meio de muita imaginação e fantasia, Lua no varal (2012) nos persuade de que a literatura, o livro," além de existir para ser admirado, para ser bonito, poderá ser uma salvação. Por isso a sugestão do sono lírico que liberta da gaiola e possibilita o sonho:"Até que a noite infinita/lhe traga o sono mais lírico/ e ele sonhando ser Ícaro/ escapa de sua gaiola/ munido de tinta e pincel" (p.9). E isso nos faz lembrar de Goethe (1749-1832): "não existe meio mais seguro para fugir do mundo do que a arte, e não há forma mais segura de se unir a ele do que a arte."

O menino, na volta do sonho, traz a lua no braço e a dependura no espaço "do quarto-crescente que é o seu" (p.10) e na Rua do Sono presentificam-se as memórias de 


\section{SEMINÁRIO DE PESQUISA EM CIÊNCIAS HUMANAS - SEPECH \\ Humanidades, Estado e desafios didático-científicos \\ Londrina, 27 a 29 de julho de 2016}

um menino sonâmbulo que escondia nuvens nos paralelepípedos da rua e a musicalidade provocada pela algazarra de cigarras zunindo múltiplas guitarras à medida em que surge o Circo Nacional de Milonga e a temporada do riso. As imagens são as mais insólitas possíveis: cobra que voa e onça com catapora (p.15)

Vale ressaltar que a irreverência da linguagem permeia todo o texto: "E no mundo cabia o Circo, o peixe e o gorila./ E no mundo cabia o riso, o palhaço, a nuvem/ e cabia também no mundo/ formiga lutando boxe... (p.19). É bem interessante a exploração da anáfora em "e" nos versos da página 20 "e a barata tirando a roupa.../ e a minhoca de patins.../e aquele gambá perfumado" (p.20) a lesma veloz que corria. Usando a anáfora, Antonio Barreto valoriza o recurso linguístico-estilístico que possibilita o diálogo, a intertextualidade e a construção de novas e possíveis leituras, atualizando a poesia e elevando-a à máxima potência as virtualidades do signo. Por meio das anáforas, a palavra poética, deixa de ser intransitivo para tornar-se feixe de relações que prismatizam o som pelos sentidos e o sentido pelos sons, a imagem pelas ideias e a ideia pelas imagens. Não se trata de recurso estilístico destituído de sentido e conteúdo.

As construções novas permeiam todo o texto: "borboleta iletrada borboletando na estrada e o pica-pau-lenhador, da escola de Datiligrafia" evoluindo para belas construções poéticas: "batendo nas teclas da infância aquilo que o tempo escrevia" (p.23). A linguagem sugestiva, conotativa, metafórica, figurada, criativa, inusitada cumpre, no livro analisado, a chamada função poética. Na definição de Jean Cohen (1974), crítico de literatura, Poesia é palavra. É linguagem. Todo o gênio do poeta reside na invenção verbal. É justamente esta forma de dizer e de expressar que me encanta em Lua no varal (2012): "era a Lua encurralada na rua enluarada/dormindo bem fresquinha numa pooça- dágua." (p. 26)

Se a poesia é uma forma peculiar de dizer, de expressar, de maneira surpreendente o livro Lua no varal revela isso: “Ali, onde o rio passava, /..._Era o tempo que andava de costas/ com gosto de azul na cacunda?/_Ou o eco assoando o nariz/ no fundo do abismo da fala? (p. 29). Para Bartolomeu Campos Queirós (1997), a literatura é um rompimento com o cotidiano da linguagem e isso só existe quando o texto abre espaço para a reflexão. A literatura não é servil, ela só existe em liberdade, o seu compromisso é com a revelação, por isso a sua função formadora.

Antonio Barreto perfeitamente nos mostra que a essência da poesia não está no próprio assunto, na expressão do sentimento, da comoção, do encantamento, mas na palavra: " e a água morrendo de medo de se afogar na enxurrada" (p.33). Por meio da aproximação de sentidos contrários, o contraste se estabelece, servindo, essencialmente, para dar ênfase aos conceitos envolvidos. Metaforicamente, estamos diante da ideia de que a poesia não tem fim e suas interpretações também não se esgotam. Jean Cohen (1974) considera que poeta é poeta não pelo que pensou ou sentiu, mas pelo que disse, uma vez que não é criador de idéias, mas de palavras. Todo seu gênio reside na invenção verbal.

A função psicológica e formadora, descritas por Candido (1972) são aqui entrevistas por meio da linguagem poética que ultrapassa sua função meramente comunicativa e se torna, ela própria, a matéria prima para a obra de arte. Em função disso, ressaltamos que na função poética o esforço do autor incide sobre a estrutura da mensagem, sobre a forma de dizer: Poesia é o texto permeado de movimento, de sentido contrário, de abertura para o outro, é o texto que rompe o equilíbrio e faz pensar. 


\title{
XI SEMINÁRIO DE PESQUISA EM CIÊNCIAS HUMANAS - SEPECH \\ Humanidades, Estado e desafios didático-científicos \\ Londrina, 27 a 29 de julho de 2016
}

(CECCANTINI, 2004, p.146). São exatamente essas várias definições e indefinições que dão à poesia riqueza e grandiosidade, pois a sua expressão pode ser multifacetada.

Para Lavínia Fávero, na poesia, o silêncio não representa uma ausência, mas uma possibilidade de sentido, pois o que o poema cala diz tanto quanto o que ele enuncia, porque sinaliza algo que está faltando. Porque afinal, em Lua no varal, o amanhecer, pode representar tanta coisa, inclusive a que não foi expressa:

\author{
Era o silêncio entre os dedos \\ da vó tricotando ternuras \\ Ou a engenharia precoce \\ $\overline{\mathrm{A}}$ mãe ensinado o que a escola \\ esquecia no alfabeto da luta? \\ - Ou era o futuro correndo \\ Nas pautas da música da aurora? (2012, p.45)
}

E assim o livro chega ao seu fim. E nós leitores e apreciadores do bom texto literário atentamos para o fato de que o fim do livro remete ao seu início, em se tratando do espaço e do contexto. "Ali, na janela da noite" (p.7), primeiro verso da primeira estrofe do livro, é retomado na última página:

\author{
"Mas é na janela da aurora \\ quando o dia tira o chapéu - \\ Que Ícaro de cabelos brancos \\ E enormes asas de cera \\ estende entre duas estrelas \\ um mágico fio de cristal. \\ E enquanto o menino dorme \\ $\mathrm{O}$ velho anjo pendura \\ Naquele varal de doçura \\ Outra Lua pintada no céu. (2012, p.54)
}

Indiretamente, por meio de muita imaginação e fantasia, Lua no varal nos persuade de que a poesia, além de existir para ser admirada, para ser bonita, ela poderá ser uma salvação, por isso a sugestão passagem do tempo com "Ícaro de cabelos brancos" (p.54).

A função social, terceira e última função descrita por Candido, se refere à identificação do leitor e de seu universo vivencial representados na obra artística. Nesse sentido, maior é o efeito dessa função quando o leitor consegue relacionar a realidade da obra às suas próprias experiências pessoais. Em Lua no varal (2012) temos, de forma metalinguística, uma das mais belas e interessantes reflexões sobre a poesia. Não há uma única definição para poema, assim como não há uma única interpretação para o texto literário.

Entretanto, dizer que um texto pode permitir várias leituras não implica, de modo algum, admitir que qualquer interpretação seja correta nem que o leitor possa dar ao texto o sentido que lhe aprouver. $\mathrm{O}$ texto que admite várias leituras contém em si indicadores dessas várias possibilidades. No seu interior aparecem figuras ou temas que 


\section{SEMINÁRIO DE PESQUISA EM CIÊNCIAS HUMANAS - SEPECH \\ Humanidades, Estado e desafios didático-científicos \\ Londrina, 27 a 29 de julho de 2016}

têm mais de um significado e que, por isso, apontam para mais de um plano de leitura. As interpretações devem encontrar apoio em elementos do texto.

As ilustrações são também muito interessantes no livro. Ora pontuando o texto, marcando o início, as pausas e o fim, ora sugerindo simbolicamente uma ideia não-dita, ou narrando uma ação, expressando emoções, ou ainda descrevendo objetos, cenários e personagens, as imagens vão além das palavras, o que nos possibilita uma dupla leitura poética: do texto e da imagem. Neste livro, duas formas de arte se juntam para tratar da poesia. Com cores vivas, o ilustrador interpreta e ilumina os múltiplos sentidos da expressão "lua no varal" encontrados nesse livro.

A ilustração da capa, que mostra uma lua branca, pendurada em varal azul num fundo preto, como se fosse vista de uma janela, sugere a metáfora do tempo (a linha do varal) e a efemeridade dele (a lua e a noite), realçada pelo paratexto da quarta página, de Joana Cavalcanti (2012):

A escrita de Antonio Barreto é cheia de tempo, infância e imaginação. Faz da palavra um feitiço de cores, sabores, cheiros, texturas e brincadeira. Aqui tudo é possível e a paisagem do quotidiano ganha outros significados. O varal não é para estender a roupa, mas os sonhos! Um fio de tempo vale muito; nele penduram-se as memórias, os sentimentos, o conhecimento e a vida.

Nas últimas páginas, estão elencadas (e não são poucas) todas as premiações recebidas por ocasião da primeira edição.

O livro Lua no varal possibilita abertura para construção de sentidos. Além das metáforas, antíteses, assonâncias e aliterações: "era a lua em disparada pela rua afora/ violando a luz de lã/ da lâmpada pálida/da aurora" (p.52), outro recurso bem interessante utilizado por Antonio Carvalho diz respeito à alusão, referência explícita à personagem mitológica de Ícaro: "Até que a noite infinita/lhe traga o sono mais lírico/ e ele sonhando ser Ícaro/ escapa de sua gaiola/ munido de tinta e pincel” (p.9) para servir de termo de comparação, e que apela à capacidade de associação de ideias do leitor. $\mathrm{O}$ recurso à alusão na Literatura pode testemunhar a relação de um autor com a tradição que representa ou com a qual se identifica. Diferentemente da mitologia grega, o Ícaro, de Lua no varal, envelhece: "Mas é na janela da aurora/ - quando o dia tira o chapéu -/ que Ícaro de cabelos brancos/ e enormes asas de cera/ estende entre duas estrelas/ um mágico fio de cristal.” (p.54)

\section{CONSIDERAÇÕES FINAIS}

Por fim, ressaltamos que a poesia mostra aos leitores que existem várias maneiras de usar as palavras e a linguagem. No livro Lua no varal, reeditado e publicado em 2012, Antonio Barreto mostra aos leitores que existem várias maneiras de usar as palavras e a linguagem: "Ali, onde a rua era curva/como a pança de Papai Noel,/ um bumbo espantou a chuva/ depois o trombone, o tarol/ e numa algazarra as cigarras/ zuniram muitas guitarras." (p.13)

Carlito Azevedo que considera a poesia "algo tão generoso que às vezes até se dá o trabalho de aparecer uma ou duas vezes um bom livro de poemas". No livro Lua no 


\section{SEMINÁRIO DE PESQUISA EM CIÊNCIAS HUMANAS - SEPECH \\ Humanidades, Estado e desafios didático-científicos \\ Londrina, 27 a 29 de julho de 2016}

varal generosidade se efetiva, pois estamos diante de texto que, do começo ao fim, é permeado de poesia.

Conforme discorremos até aqui, de acordo com Candido (1972), a literatura tem o poder de atuar na formação do indivíduo. Ainda, nas palavras de Candido, "a Literatura não corrompe nem edifica, portanto; mas, trazendo livremente em si o que chamamos o bem e o que chamamos o mal, humaniza em sentido profundo, porque faz viver." (1972, p. 806)

\section{REFERÊNCIAS BIBLIOGRÁFICAS}

AZEVEDO, Carlito. Sambaquis. Poesia a queima roupa. Disponível em: < https://sambaquis.wordpress.com/category/poesia-a-queima-roupa/page/8/>. Acesso 22 de maio de 2016.

BARRETO, Antonio. Lua no varal. Ilustrações Paulo Bernardo Vaz. Belo Horizonte: Miguilim, 2012.

CANDIDO, Antonio. A Literatura e a formação do homem. Ciência e cultura, São Paulo. v. 9, n. 24, p. 803-809, set. 1972.

CECCANTINI, João Luís C. T. Literatura Infantil - a narrativa. In.: Pedagogia Cidadã: cadernos de formação: Lingua Portuguesa/ João Luís Cardoso Tápias Ceccantini, Rony Farto Pereira, Juvenal Zanchetta Junior, organizadores. São Paulo: UNESP, PróReitoria de Graduação, 2004. Vol.2.

COHEN, Jean. Estrutura da linguagem poética. Tradução de Álvaro Lorencini e Anne Arnichand. São Paulo: Cultrix, 1974.

CRUZ, Edson (Org). O que é poesia? Rio de Janeiro: Confraria do vento/Calibán, 2009.

FÁVERO. Lavínia. Isto é um poema que cura os peixes - guia de leitura para o professor. Disponívem em: < http://www.edicoessm.com.br/backend/public/recursos/ Guia20de20leitura20Isto 20e 20um 20poema20que20cura20os20peixes.pdf $>$. Acesso em 01 ago. 2015.1

GOETHE, Johann Wolfgang von. Máximas e reflexões. Rio de Janeiro: Forense Universitária, 2003.

QUEIRÓS, Bartolomeu Campos. Menino Temporão. In: PAULINO, Graça (org.). $O$ Jogo do livro infantil: textos selecionados para a formação de educadores. Belo Horizonte: Dimensão, 1997. 